\title{
Granulocyte-macrophage colony-stimulating factor is a key mediator in experimental osteoarthritis pain and disease development
}

\author{
Andrew D Cook ${ }^{1 *}$, Jarrad Pobjoy ${ }^{1}$, Stefan Steidl ${ }^{2}$, Manuela Dürr², Emma L Braine ${ }^{1}$, Amanda L Turner', \\ Derek C Lacey ${ }^{1}$ and John A Hamilton ${ }^{1}$
}

\begin{abstract}
Introduction: Granulocyte-macrophage colony-stimulating factor (GM-CSF) has been shown to be important in the development of inflammatory models of rheumatoid arthritis and there is encouraging data that its blockade may have clinical relevance in patients with rheumatoid arthritis. The aims of the current study were to determine whether GM-CSF may also be important for disease and pain development in a model of osteoarthritis.

Methods: The role of GM-CSF was investigated using the collagenase-induced instability model of osteoarthritis. We studied both GM-CSF-/- mice and wild-type (C57BL/6) mice treated prophylactically or therapeutically with a monoclonal antibody to GM-CSF. Disease development (both early and late) was evaluated by histology and knee pain development was measured by assessment of weight distribution.
\end{abstract}

Results: In the absence of GM-CSF, there was less synovitis and matrix metalloproteinase-mediated neoepitope expression at week 2 post disease induction, and less cartilage damage at week 6. GM-CSF was absolutely required for pain development. Therapeutic neutralization of GM-CSF not only abolished the pain within 3 days but also led to significantly reduced cartilage damage.

Conclusions: GM-CSF is key to the development of experimental osteoarthritis and its associated pain. Importantly, GM-CSF neutralization by a therapeutic monoclonal antibody-based protocol rapidly and completely abolished existing arthritic pain and suppressed the degree of arthritis development. Our results suggest that it would be worth exploring the importance of GM-CSF for pain and disease in other osteoarthritis models and perhaps clinically for this form of arthritis.

\section{Introduction}

Granulocyte-macrophage colony-stimulating factor (GMCSF) was originally defined as a hemopoietic growth factor [1]. However, it can act on mature myeloid cells [2] and it has other functions, acting as a proinflammatory cytokine [2-5] and in dendritic cell function [6]. More specifically, its depletion can have profound effects on disease severity and progression in many inflammatory arthritis models [7-10]; encouragingly, initial results suggest that antibody blockade of the GM-CSF receptor has therapeutic benefit in rheumatoid arthritis (RA) [11,12].

\footnotetext{
* Correspondence: adcook@unimelb.edu.au

${ }^{1}$ Arthritis and Inflammation Research Centre, Department of Medicine, The University of Melbourne, Victoria, 3010, Australia

Full list of author information is available at the end of the article
}

Osteoarthritis (OA) is the most common rheumatic disorder. The pathogenic characteristics of OA are loss of cartilage with associated underlying bony changes consisting of sclerosis, subchondral bone collapse, bone cysts, and osteophyte formation [13]. Pain is one of the most important symptoms of OA as it causes a significant impairment in function. The etiology of OA is likely to be multifactorial, with mechanical, metabolic and inflammatory contributions. Recent histologic evidence indicates that synovitis can be an early feature in OA, even in joints where it could not be detected clinically [14-16], with a mixed inflammatory infiltrate consisting mainly of macrophages and with proinflammatory mediator production (for example, TNF, IL-1 $\beta$ ) $[17,18]$. It has been argued that

\section{C) Biomed Central}

(C) 2012 Cook et al.; licensee BioMed Central Ltd. This is an open access article distributed under the terms of the Creative Commons Attribution License (http://creativecommons.org/licenses/by/2.0), which permits unrestricted use, distribution, and reproduction in any medium, provided the original work is properly cited. 
OA synovial inflammation is qualitatively similar to that in RA, differing only in magnitude [19].

The collagenase-induced OA model is based on the induction of joint instability by intra-articular injection of collagenase. This causes weakening of the ligaments, leading to an OA-like pathology, including cartilage matrix erosion and osteophyte formation within 6 weeks $[20,21]$. It is macrophage-dependent; the macrophages mediate osteophyte formation and fibrosis in the early stages [21,22]. Given that the major functions of GMCSF appear to be as a pro-survival and 'activating' factor for myeloid cells [2], in the current study we investigated whether this experimental OA model is dependent on GM-CSF. As pain is an important symptom of OA, with a complex relationship with tissue damage [23], the requirement of GM-CSF for development of such pain in the collagenase-induced arthritis model was also sought. We have recently shown that GM-CSF is key to the development of arthritic pain in a number of inflammatory arthritis models [24].

We report here that GM-CSF is an important mediator in the progression of both the pain and disease in this OA-like model.

\section{Methods}

Mice

GM-CSF gene-deficient (GM-CSF-/-) mice were backcrossed onto the C57BL/6 background for 12 generations $[8,25,26]$. Mice of both sexes, 8 to 12 weeks of age, were used in all experiments. Mice were housed five per cage and the male:female distribution was comparable for all experimental groups. All experiments were approved by The University of Melbourne Animal Ethics Committee.

\section{Collagenase-induced arthritis}

Arthritis was induced as published [21]. Briefly, mice received an intra-articular injection of one unit of collagenase type VII (Sigma-Aldrich, St. Louis, Missouri, USA) on days 0 and 2 to induce joint instability. Because of the focal nature of the damage seen in this model [27], the region of the joint most affected (lateral or medial side) is dependent on the placement of the initial injection (that is, from which side). This placement varied between experiments but for individual experiments was kept constant. Mice were sacrificed at weeks 1, 2 and 6 post collagenase injection and knee joints were collected for histology.

\section{Pain readings}

As an indicator of knee pain, the differential distribution of weight on the hind limbs was measured using an incapacitance meter (IITC Life Science Inc., Woodland Hills, CA, USA). This validated technique for arthritic knee pain $[24,28,29]$ measures changes in weight distribution between the arthritic hind limb relative to the nonarthritic hind limb. Mice were allowed to acclimatize to the equipment on three occasions prior to experiment. Weight placed on each limb was measured over a 5-second period. Three separate measurements were taken per mouse for each time point by an independent observer without knowledge of the experimental groups. The readings were then averaged. Results are expressed as a percentage of the weight placed on the arthritic limb verses the contralateral control limb (arthritic limb/control limb $\times 100)$. A decrease in weight applied to the arthritic limb (that is, a reading $<100$ ) indicates pain [24].

\section{Antibody treatment}

Mice with collagenase-induced arthritis were treated by intraperitoneal injection, either prophylactically or therapeutically, with anti-mouse GM-CSF monoclonal antibody (mAb; MP1-22E9, AbD Serotec, Oxford, UK) or IgG2a isotype control $\mathrm{mAb}$ (AbD Serotec) [7,10]. For prophylactic treatment, mice were given $250 \mu \mathrm{g}$ per mouse per treatment of anti-GM-CSF or control mAb beginning 4 days prior to the first collagenase injection (day 0), with subsequent treatment on days -2 and 0 , and thereafter three times per week for 6 weeks. Serum samples were collected at 2, 4 and 6 weeks post collagenase injection and investigated for their anti-GM-CSF mAb concentration. High serum levels of MP1-22E9 were detected at each time point, which, in the light of published potency data on MP1-22E9 [30], prompted us to reduce the dose used and extend the dosing intervals for the therapeutic treatment. For therapeutic treatment, mice were given $150 \mu \mathrm{g}$ per mouse per treatment of anti-GM-CSF or control mAb twice per week following the onset of pain, until the end of the experiment at 6 weeks. The onset of pain was defined as a significant difference in the average pain compared with $\mathrm{t}=0$.

\section{Histology}

At termination after arthritis induction, the knee joints were removed, fixed, decalcified, and paraffin embedded, as previously described $[7,10]$. Frontal sections $(5 \mu \mathrm{m})$ were stained with either $\mathrm{H} \& \mathrm{E}$ to examine joint architecture or with safranin $\mathrm{O}$, fast green and hematoxylin for proteoglycan loss, and evaluated by two independent observers without knowledge of the experimental groups, using the histologic assessment as follows.

Week 1 and 2 sections were scored for cellular infiltration and synovial hyperplasia from 0 (normal) to 3 (severe) as previously [21]. Week 6 sections were scored for cartilage damage in terms of the OA depth into cartilage (grade) and amount of cartilage affected (stage), as described by van Lent et al. [31]. This scoring system is modified from that of Pritzker et al. [32] to make it more suitable for measuring pathologic changes in murine 
cartilage. OA grade was scored from 0 (normal) to 6 (bone loss, remodeling, deformation) and OA stage from 0 ( $<10 \%$ involvement) to 4 ( $>50 \%$ involvement) for the lateral tibia, lateral femur, medial tibia, and medial femur. The grade and stage were then multiplied to give an overall OA score, to represent a combined assessment of OA severity and extent [31]. Up to six sections were scored per mouse, and an average taken. Safranin $\mathrm{O}$-stained sections were used to assess the presence of osteophytes at the lateral and medial femur and tibia. Their size was analyzed using the image software Image J (National Institutes of Health, Bethesda, MD, USA ). The mean area per knee joint (three sections) was calculated and expressed in arbitrary units.

\section{Immunohistochemistry}

The matrix metalloproteinase (MMP)-induced neoepitope, DIPEN, was detected as published [33]. Briefly, paraffinembedded sections were deparaffinized and rehydrated, and endogenous peroxidise blocked with $3 \%$ (vol/vol) $\mathrm{H}_{2} \mathrm{O}_{2}$ (Sigma-Aldrich). Sections were digested with chondroitinase $A B C$ (0.1 units $/ \mathrm{mL}$; Sigma-Aldrich) for 2 hours at $37^{\circ} \mathrm{C}$ to remove chondroitin sulfate from the proteoglycans, prior to blocking with $5 \%$ goat serum. Sections were then incubated overnight at $4{ }^{\circ} \mathrm{C}$ with anti-DIPEN [34] (a gift from A/Professor Amanda Fosang, University of Melbourne, Victoria, Australia) and detected with a biotinylated anti-rabbit IgG (Dako, Glostrup, Denmark), followed by a streptavidin-peroxidase conjugate (BD Biosciences, San Jose, CA, USA). Peroxidase activity was demonstrated by incubation with 3,3'-diaminobenzidine/ tetrahydrochloride (Sigma-Aldrich) $-\mathrm{H}_{2} \mathrm{O}_{2}$ solution. Slides were counterstained with hematoxylin.

DIPEN staining was scored from 0 to 3 based on amount of staining, where $0=$ no staining and $3=\max$ imal staining, as previously described [35].

\section{Statistics}

For pain readings, Student's t-test or two-way analysis of variance was used. For histologic scores, the Mann-Whitney two-sample rank test or two-way analysis of variance was used; values are expressed as the mean \pm standard error of the mean. $P * 0.05$ was considered statistically significant.

\section{Results \\ GM-CSF is important throughout collagenase-induced arthritis progression}

Several RA-like inflammatory arthritis models have been shown to be GM-CSF dependent [7-10]. To determine whether an OA-like model was also dependent on GMCSF, histology was performed on the joints of C57BL/6 (wild-type) and GM-CSF-/- mice at 6 weeks post collagenase intra-articular injection and disease scored according to the published protocol [31]. At this time point, synovitis was not evident (data not shown). GM-CSF-/- mice showed less knee joint tissue damage in the lateral tibia $(P=0.003)$, lateral femur $(P=0.02)$ and medial tibia $(P=$ 0.001 ) compared with wild-type mice (Figure $1 \mathrm{~A}, \mathrm{~B})$. Overall the mean arthritis score for all regions was significantly lower in GM-CSF-/- mice compared with that in wildtype mice $(P=0.002)$ (Figure $1 \mathrm{~B})$.

Synovitis and osteophyte formation have previously been reported to be present early in disease development in this model [21]. Therefore, a role for GM-CSF in the development of these disease features was examined at 1 and 2 weeks post collagenase injection. Mild synovitis was observed in wild-type mice at both time points (Figure 2A, B); however, this was virtually absent in GM-CSF-/- mice with only one mouse at week 1 having a very low score. Expression of the MMP-generated proteoglycan neoepitope, DIPEN, was assessed by immunohistochemistry as a measure of MMP-mediated cartilage damage [36]. At week 2 , there was significantly greater expression of the neoepitope in the cartilage of wild-type mice compared with that in GM-CSF- $/$ - mice $(P=0.02$; Figure $2 \mathrm{C}, \mathrm{D})$. At both 1 and 2 weeks, there was a trend towards there being fewer osteophytes in GM-CSF-/- mice compared with wild-type mice, and a trend towards the mean osteophyte size being smaller in the former strain (data not shown). Therefore, GM-CSF plays a role throughout the arthritis progression in this model.

\section{Collagenase-induced arthritis pain is GM-CSF dependent}

We have recently shown that GM-CSF is key to the development of arthritic pain in a number of inflammatory arthritis models [24]. We next explored whether GM-CSF was critical also for joint pain development in this OA-like model by administering a neutralizing $\mathrm{mAb}$ to GM-CSF prophylactically. Pain has not been recorded in this model. Pain was measured by the changes in weight distribution using an incapacitance meter and has been validated previously to measure arthritic knee pain $[24,28,29]$. To assess whether there is pain induction, $\mathrm{C} 57 \mathrm{BL} / 6$ mice received control $\mathrm{mAb}$ beginning 4 days prior to collagenase injection. Knee pain was evident from around 3 weeks and remained significant until 6 weeks when the mice were sacrificed (Figure 3A). Mice pretreated with anti-GM-CSF $\mathrm{mAb}$, however, did not develop any detectable pain. From around day 22, control mAb-treated mice showed significantly more pain compared with anti-GM-CSF mAbtreated mice $(P<0.05)$.

In agreement with the GM-CSF-/- mouse arthritis data above, at 6 weeks the anti-GM-CSF mAb-treated mice also had significantly less arthritis in the lateral femur $(P=0.03)$ and medial femur $(P=0.004)$, compared with the control mAb-treated group (Figure $3 \mathrm{~B}$ ). To confirm that the isotype control mAb had no effect 


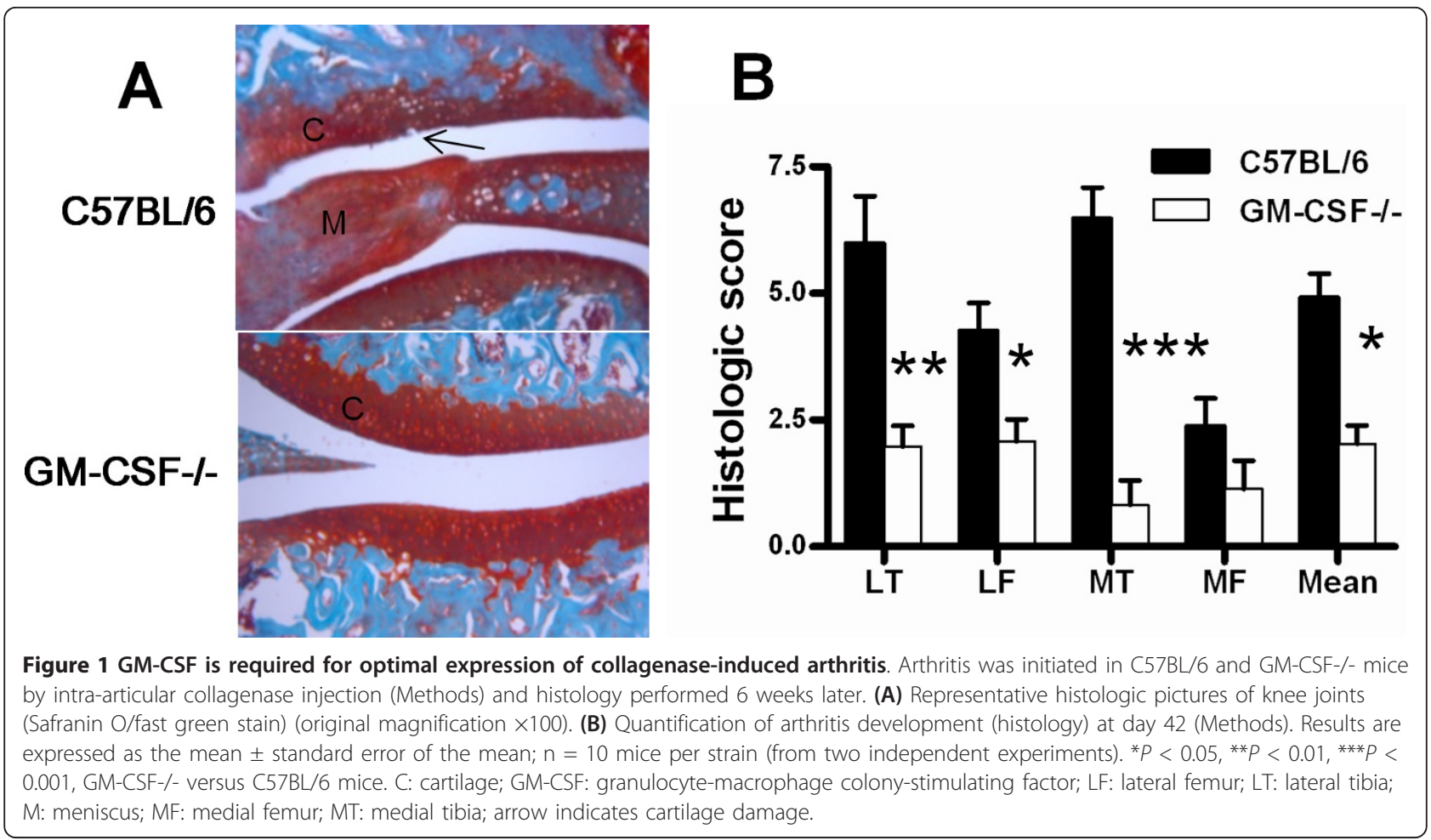

on disease development, a PBS control group was also included. There was no significant difference in the histologic scores for the PBS-treated group and the control mAb-treated group for any of the regions scored (data not shown).The mean level of arthritis development was significantly lower in the anti-GM-CSF mAb-treated group $(P=0.003)$. Once again, synovitis could not be detected at this time point in any of the mice, and in mice where osteophytes were detected, they were significantly smaller in the anti-GM-CSF mAb-treated group compared with the control mAb-treated group (mean size: anti-GM-CSF mAb-treated group, $238 \pm 114$ versus control mAb-treated group, $577 \pm 48, P<0.05$ ).

Thus GM-CSF is an essential mediator of knee pain progression in this OA-like model.

\section{Therapeutic neutralization of GM-CSF ameliorates both collagenase-induced arthritic pain and disease development}

The mAb-based approach allowed us to next determine whether therapeutic treatment with anti-GM-CSF mAb could also suppress the pain and disease, and how rapidly it might reverse the pain. Once knee pain was evident in collagenase-injected C57BL/6 mice, those with similar pain readings were treated with either control $\mathrm{mAb}$ or anti-GM-CSF mAb twice weekly until week 6 . Treatment with the control $\mathrm{mAb}$ had no effect on the pain, which continued to increase (Figure 4A). Treatment with antiGM-CSF mAb completely suppressed the pain within 3 days, this being the earliest time at which it was measured following $\mathrm{mAb}$ treatment. This abolition of knee pain was maintained until sacrifice (day 42). By histology, at 6 weeks the anti-GM-CSF mAb-treated mice also had significantly milder disease in the medial tibia $(P<0.01)$ and medial femur $(P<0.05)$ regions of the joints (Figure 4B,C) with the mean level of arthritis development also being significantly lower in the anti-GM-CSF mAb-treated group for this therapeutic treatment protocol. Once again, in mice where osteophytes were detected, they were significantly smaller following anti-GM-CSF mAb treatment as compared with control mAb treatment (mean size: $267 \pm$ 17 versus $406 \pm 14, P<0.05)$.

\section{Discussion}

We demonstrated above for the first time that GM-CSF is required for both pain and optimal disease development in a joint instability OA model. Furthermore, GM-CSF neutralization by a therapeutic mAb-based protocol rapidly and completely abolished existing arthritic pain. Experimental OA, induced by intra-articular collagenase injection as above, has been shown to share some important features with human OA, such as the development of osteophytes and cartilage erosion [20,21]. There is also a low grade inflammatory response (synovitis), which can also be seen in the human disease [37]. The mild synovitis observed early in disease development was virtually absent when GM-CSF was not present. This is in agreement with previous studies using systemic inflammatory models of 


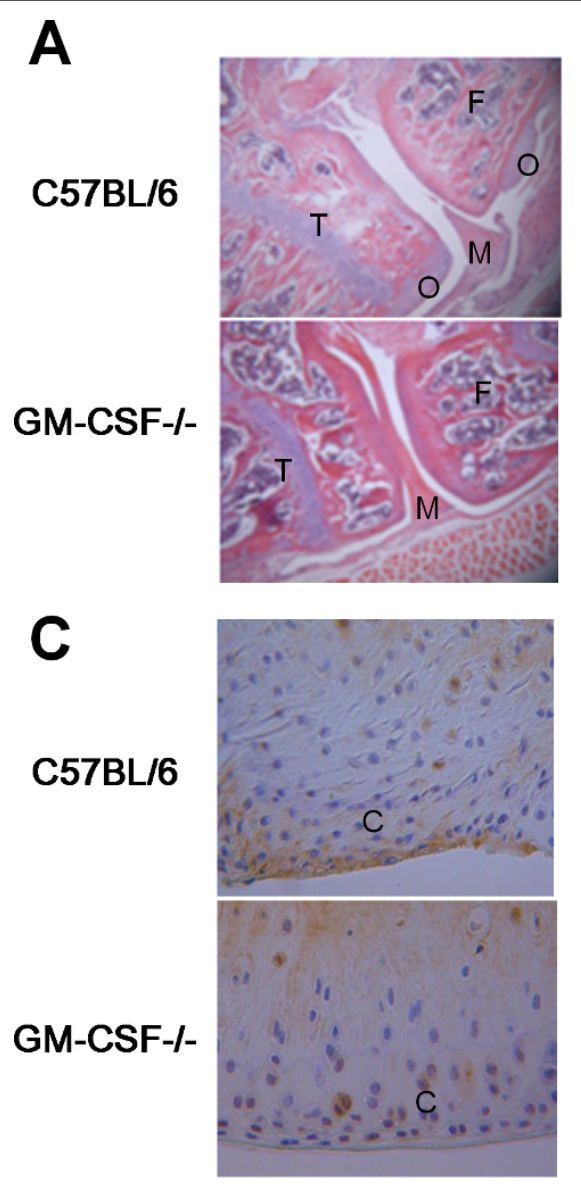

B

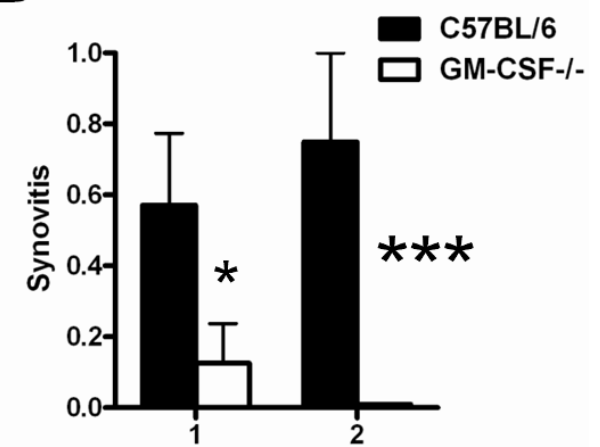

Weeks post disease induction

D

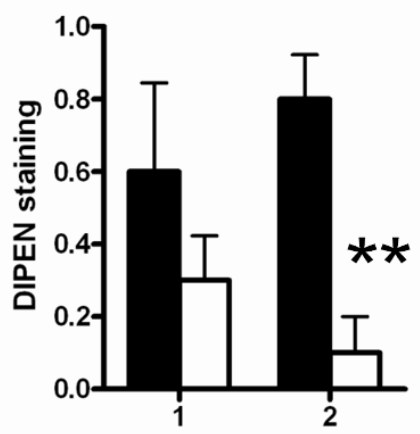

Weeks post disease induction

Figure $2 \mathrm{GM}-\mathrm{CSF}$ is required for optimal synovitis and cartilage breakdown associated with collagenase-induced arthritis. Arthritis was initiated in C57BL/6 and GM-CSF-/- mice by intra-articular collagenase injection and histology performed 1 and 2 weeks later. (A) Representative histologic pictures of knee joints at 2 weeks (original magnification $\times 100$ ). (B) Quantification of synovitis. (C) Representative DIPEN staining in knee joints at 2 weeks (original magnification $\times 125$ ). (D) Quantification of DIPEN staining. Results are expressed as the mean \pm standard error of the mean; $\mathrm{n}=5$ to 8 mice per strain per time point (from two independent experiments). ${ }^{*} P=0.05, * * P=0.02,{ }^{* * *} P=0.002, \mathrm{GM}-\mathrm{CSF}-/$ - versus C57BL/6 mice. C: cartilage; F: femur; GM-CSF: granulocyte-macrophage colony-stimulating factor M: meniscus; O: osteophyte; T: tibia.

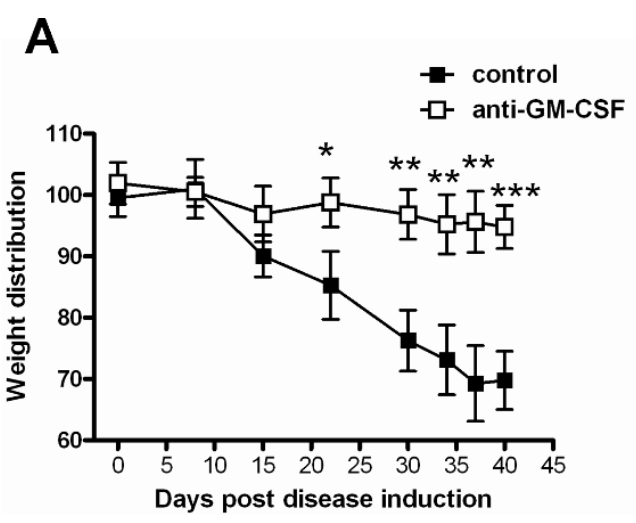

B

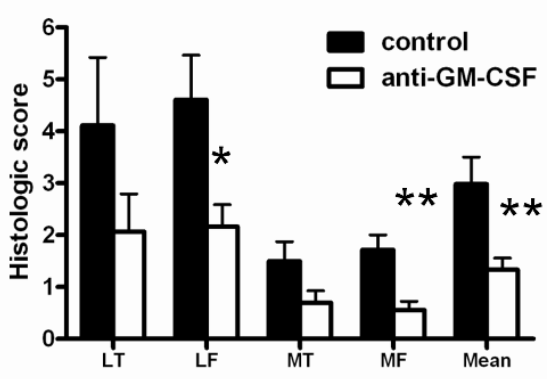

Figure 3 Pain in collagenase-induced arthritis is GM-CSF dependent. C57BL/6 mice were treated prophylactically (from day -4) with antiGM-CSF or isotype control monoclonal antibody. (A) Change in weight distribution (pain) (Methods) over time. (B) Quantification of arthritis development (histology) at day 42. Results are expressed as the mean \pm standard error of the mean; $\mathrm{n}=10$ to 15 mice per group (from two independent experiments). ${ }^{*} P<0.05,{ }^{* *} P<0.01,{ }^{* *} P<0.001$, control versus anti-GM-CSF. GM-CSF: granulocyte-macrophage colony-stimulating factor; LF: lateral femur; LT: lateral tibia; MF: medial femur; MT: medial tibia. 


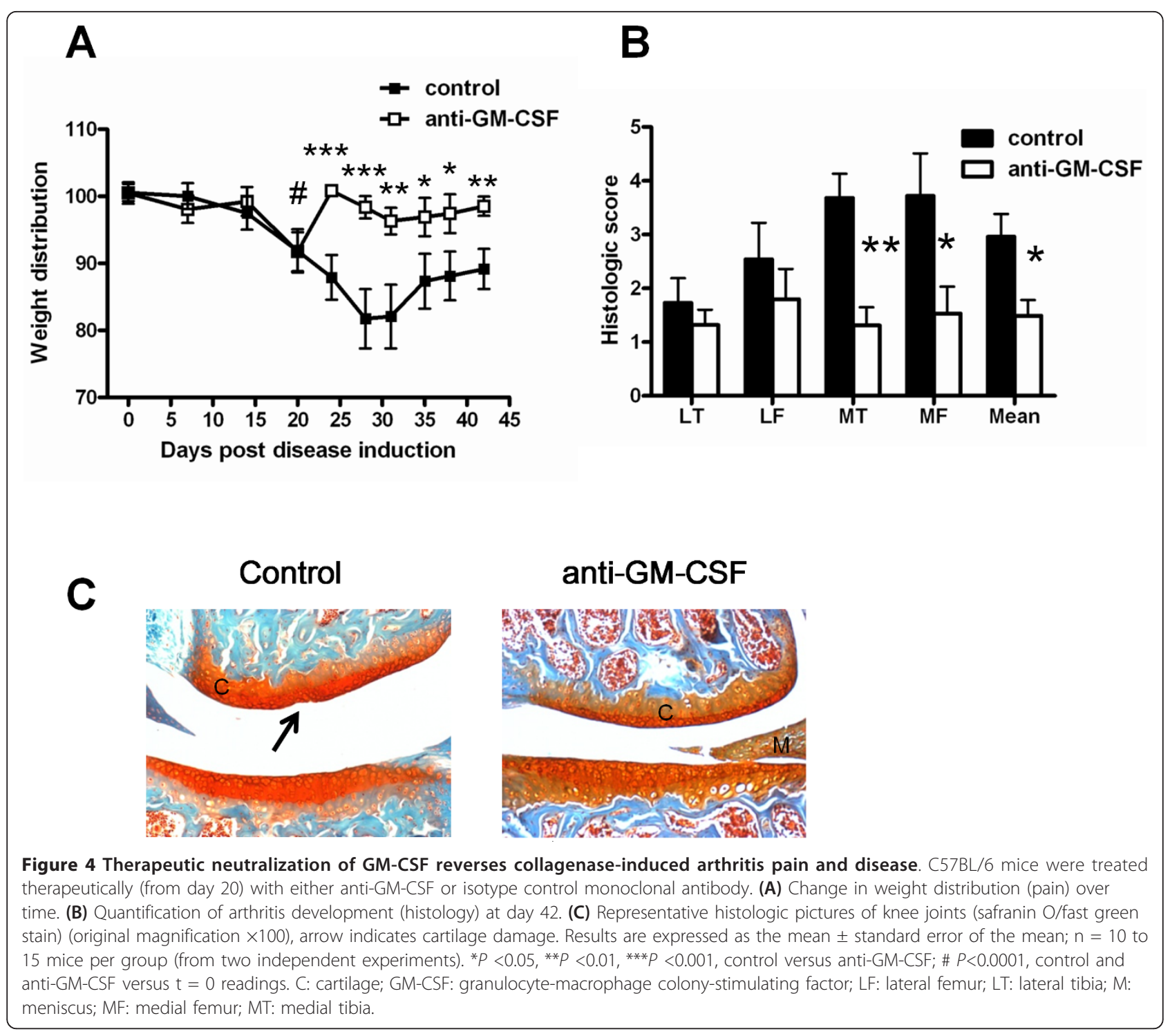

arthritis in which blockade or absence of GM-CSF led to a reduced inflammatory response and fewer macrophages in the joint $[8,10]$. Synovial macrophages have been shown to be important in this OA-like model, with both synovial inflammation and cartilage damage being ameliorated when they are selectively depleted from the synovial lining layer by clodronate liposomes [21]. As GM-CSF can directly promote macrophage survival [38], its neutralization may also lead to direct depletion of joint macrophages, in this case by apoptosis [38]. In the current study, the degree of MMP-mediated cartilage damage was also lower in the absence of GM-CSF, suggesting that GM-CSF may be important for sustained and ongoing joint damage, possibly by limiting synovial macrophage activation in addition to their numbers $[2,4,38]$.

Osteophyte formation, which is a common feature of $\mathrm{OA}$ and which may be a repair mechanism to help stabilize joints [39], is prevented by synovial macrophage depletion in the collagenase-induced model [21]. An association between osteophytes and pain has been reported for hand OA [40]. In the absence of GM-CSF, the size of the osteophytes formed was smaller than in the presence of GM-CSF. This may be related to the lack of pain seen in the absence of GM-CSF. It could also indicate some requirement of (GM-CSF dependent) synovitis for osteophyte development, as has been previously suggested [41]; however, given there was still some osteophyte formation present in GM-CSF-/- mice, other factors may also be important, such as transforming growth factor $\beta$ [42]. The degree of cartilage damage seen at 6 weeks post collagenase injection in the absence of GM-CSF was significantly decreased compared with that in wild-type mice. Interestingly, antibody-mediated GM-CSF blockade both prevented (prophylactic treatment) and reversed completely 
(therapeutic treatment) the arthritic pain and modulated the degree of osteoarthritic changes in the joint, indicating that GM-CSF is important both in the early and late stages in this model, even though the features of the model change over time. Of note, the neutralization of GM-CSF abolished existing pain within 3 days, the earliest time point measured. The effectiveness of the therapeutic protocol was similar to the findings for disease progression in systemic inflammatory and autoimmune models $[7,10]$. In addition to its direct effects on macrophages, GM-CSF may also have direct effects on neuronal sensitization in the OA lesion, similar to that suggested by Schweizerhof et al. [43] for bone cancer pain. Knee pain was evident 3 weeks post collagenase injection. The synovitis seen early in disease development in wild-type mice thus did not lead to any detectable pain, that is, a difference in weight distribution, unlike in more severe inflammatory models of arthritis $[24,28,29]$. This observation fits with the mild nature of the inflammatory response in this model. It would be of interest to determine the degree of synovitis at 3 weeks post collagenase injection, at the time of detectable pain, and to determine the effect of GM-CSF blockade at this time point on the synovitis. Recently, van Lent et al. [31] showed that synovitis peaks at week 2 in this model, before we were able to detect pain, further suggesting that the synovitis alone is unlikely to account for the pain. Exactly how GM-CSF is acting at the different stages is currently being investigated.

For the collagenase-induced model, cartilage damage is also less in IL-1 $\beta$-/- mice [44], suggesting a link between GM-CSF and IL-1. Such a link has been found before with the GM-CSF dependence of an IL-1 $\beta$-induced inflammatory monoarthritis model $[8,24]$, consistent with the concept of a 'colony-stimulating factor network' linking GM-CSF, IL-1, and other cytokines $[2,4,45]$. That such a link between IL-1 and GM-CSF may also be operating in the collagenase-induced arthritis model is supported by the fact that IL-1 can enhance MMP-mediated DIPEN neoepitope expression in cartilage [46], similar to our data above for GM-CSF and neoepitope expression.

\section{Conclusions}

From the above findings, it is proposed that GM-CSF is a key mediator of both pain and disease development in an experimental model of OA, in addition to its known role (s) in RA models. Both prophylactic and therapeutic blockade of GM-CSF were effective at ameliorating both pain and disease. Results from clinical trials assessing the role of GM-CSF in RA are encouraging [11,12]. Our results here suggest that it would be worth exploring the importance of GM-CSF for the pain and disease in other OA models and perhaps clinically for this form of arthritis.

\section{Acknowledgements}

We thank Jennifer Davis and Lara Mizhiritsky for assistance with the maintenance and care of the mice, and Amanda J Fosang for the antibody against DIPEN. This work was supported by grants from MorphoSys AG and the National Health and Medical Research Council (NHMRC), and by a NHMRC Senior Principal Research Fellowship (JAH).

\section{Abbreviations}

GM-CSF: granulocyte-macrophage colony-stimulating factor; H \& E: hematoxylin and eosin; IL: interleukin; mAb: monoclonal antibody; MMP: matrix metalloproteinase; OA: osteoarthritis; PBS: phosphate-buffered saline; RA: rheumatoid arthritis; TNF: tumor necrosis factor.

\section{Author details}

${ }^{1}$ Arthritis and Inflammation Research Centre, Department of Medicine, The University of Melbourne, Victoria, 3010, Australia. ${ }^{2}$ MorphoSys AG, LenaChrist-Strasse 48, Martinsried/Planegg, 82152, Germany.

\section{Authors' contributions}

ADC conceived the study, and participated in its design and coordination, carried out the pain readings, and drafted the manuscript. SS and MD participated in the design of the study. JP, ELB, and ALT carried out the OA experiments and histology. DCL carried out the immunohistochemistry. JAH conceived the study and participated in its design and helped draft the manuscript. All authors read and approved the final manuscript.

\section{Competing interests}

SS is a full-time employee of MorphoSys AG, Germany. JAH has received consulting fees from MorphoSys AG, Germany (less than $\$ 10,000$ a year). MD was a full-time employee of MorphoSys AG, Germany, until 2011. MorphoSys AG, Germany, have partially funded the work in this manuscript. Patent applications from the University of Melbourne (ADC, JAH) are pending on the treatment of OA and pain by using GM-CSF antagonists. MorphoSys AG hold patents on anti-GM-CSF antibodies.

Received: 27 April 2012 Revised: 2 August 2012

Accepted: 20 September 2012 Published: 20 September 2012

\section{References}

1. Burgess AW, Metcalf D: The nature and action of granulocytemacrophage colony stimulating factors. Blood 1980, 56:947-958.

2. Hamilton JA: Colony-stimulating factors in inflammation and autoimmunity. Nat Rev Immunol 2008, 8:533-544.

3. Hamilton JA, Stanley ER, Burgess AW, Shadduck RK: Stimulation of macrophage plasminogen activator activity by colony-stimulating factors. J Cell Physiol 1980, 103:435-445.

4. Hamilton JA: Rheumatoid arthritis: opposing actions of haemopoietic growth factors and slow-acting anti-rheumatic drugs. Lancet 1993, 342:536-539.

5. Fleetwood AJ, Lawrence T, Hamilton JA, Cook AD: Granulocytemacrophage colony-stimulating factor (CSF) and macrophage CSFdependent macrophage phenotypes display differences in cytokine profiles and transcription factor activities: implications for CSF blockade in inflammation. J Immunol 2007, 178:5245-5252.

6. Naik SH, Metcalf D, van Nieuwenhuijze A, Wicks I, Wu L, O'Keeffe M, Shortman K: Intrasplenic steady-state dendritic cell precursors that are distinct from monocytes. Nat Immunol 2006, 7:663-671.

7. Cook AD, Braine EL, Campbell IK, Rich MJ, Hamilton JA: Blockade of collagen-induced arthritis post-onset by antibody to granulocytemacrophage colony-stimulating factor (GM-CSF): requirement for GMCSF in the effector phase of disease. Arthritis Res 2001, 3:293-298.

8. Yang YH, Hamilton JA: Dependence of interleukin-1-induced arthritis on granulocyte-macrophage colony-stimulating factor. Arthritis Rheum 2001, 44:111-119. 
9. Plater-Zyberk C, Joosten LA, Helsen MM, Koenders MI, Baeuerle PA, van den Berg WB: Combined blockade of granulocyte-macrophage colony stimulating factor and interleukin 17 pathways potently suppresses chronic destructive arthritis in a tumour necrosis factor alphaindependent mouse model. Ann Rheum Dis 2009, 68:721-728.

10. Cook AD, Turner AL, Braine EL, Pobjoy J, Lenzo JC, Hamilton JA: Regulation of systemic and local myeloid cell subpopulations by bone marrow cellderived granulocyte-macrophage colony-stimulating factor in experimental inflammatory arthritis. Arthritis Rheum 2011, 63:2340-2351.

11. Burmester GR, Feist $E$, Sleeman MA, Wang B, White B, Magrini F: Mavrilimumab, a human monoclonal antibody targeting GM-CSF receptor-alpha, in subjects with rheumatoid arthritis: a randomised, double-blind, placebo-controlled, phase I, first-in-human study. Ann Rheum Dis 2011, 70:1542-1549.

12. Burmester GR, Weinblatt ME, Barbarash O, Vatutin M, Szombati I, Stoilov R, Matsievskaya G, Venalis A, Esfandiari E, Grove G, Saurigny D, Sleeman MA, Godwood A, Magrini F: Mavrilimumab (an anti-GM-CSFRa monoclonal antibody) in subjects with rheumatoid arthritis: results of a phase 2 randomized, double-blind, placebo-controlled study [abstract]. Arthritis Rheum 2011, 63:4044.

13. lannone F, Lapadula G: The pathophysiology of osteoarthritis. Aging Clin Exp Res 2003, 15:364-372

14. Spector TD, Hart DJ, Nandra D, Doyle DV, Mackillop N, Gallimore JR, Pepys MB: Low-level increases in serum C-reactive protein are present in early osteoarthritis of the knee and predict progressive disease. Arthritis Rheum 1997, 40:723-727.

15. Sowers M, Jannausch M, Stein E, Jamadar D, Hochberg M, Lachance L: Creactive protein as a biomarker of emergent osteoarthritis. Osteoarthritis Cartilage 2002, 10:595-601.

16. Haywood L, McWilliams DF, Pearson Cl, Gill SE, Ganesan A, Wilson D, Walsh DA: Inflammation and angiogenesis in osteoarthritis. Arthritis Rheum 2003, 48:2173-2177.

17. Farahat MN, Yanni G, Poston R, Panayi GS: Cytokine expression in synovial membranes of patients with rheumatoid arthritis and osteoarthritis. Ann Rheum Dis 1993, 52:870-875.

18. Bondeson J, Blom AB, Wainwright S, Hughes C, Caterson B, van den Berg WB: The role of synovial macrophages and macrophage-produced mediators in driving inflammatory and destructive responses in osteoarthritis. Arthritis Rheum 2010, 62:647-657.

19. Haraoui B, Pelletier JP, Cloutier JM, Faure MP, Martel-Pelletier J: Synovial membrane histology and immunopathology in rheumatoid arthritis and osteoarthritis. In vivo effects of antirheumatic drugs. Arthritis Rheum 1991, 34:153-163.

20. van der Kraan PM, Vitters EL, van de Putte $L B$, van den Berg WB: Development of osteoarthritic lesions in mice by "metabolic" and "mechanical" alterations in the knee joints. Am J Pathol 1989, 135:1001-1014

21. Blom $A B$, van Lent $P L$, Holthuysen $A E$, van der Kraan PM, Roth J, van Rooijen N, van den Berg WB: Synovial lining macrophages mediate osteophyte formation during experimental osteoarthritis. Osteoarthritis Cartilage 2004, 12:627-635.

22. Blom $\mathrm{AB}$, Brockbank $\mathrm{SM}$, van Lent $\mathrm{PL}$, van Beuningen $\mathrm{HM}$, Geurts J, Takahashi N, van der Kraan PM, van de Loo FA, Schreurs BW, Clements K, Newham P, van den Berg WB: Involvement of the Wnt signaling pathway in experimental and human osteoarthritis: prominent role of Wntinduced signaling protein 1. Arthritis Rheum 2009, 60:501-512.

23. Sofat N, Ejindu V, Kiely P: What makes osteoarthritis painful? The evidence for local and central pain processing. Rheumatology (Oxford) 2011, 50:2157-2165.

24. Cook AD, Pobjoy J, Sarros S, Steidl S, Durr M, Lacey DC, Hamilton JA: Granulocyte-macrophage colony-stimulating factor is a key mediator in inflammatory and arthritic pain. Ann Rheum Dis 2012

25. Stanley E, Lieschke GJ, Grail D, Metcalf D, Hodgson G, Gall JA, Maher DW, Cebon J, Sinickas V, Dunn AR: Granulocyte/macrophage colonystimulating factor-deficient mice show no major perturbation of hematopoiesis but develop a characteristic pulmonary pathology. Proc Natl Acad Sci USA 1994, 91:5592-5596.

26. Campbell IK, Rich MJ, Bischof RJ, Dunn AR, Grail D, Hamilton JA: Protection from collagen-induced arthritis in granulocyte-macrophage colonystimulating factor-deficient mice. J Immunol 1998, 161:3639-3644.
27. van der Kraan PM, Vitters EL, van Beuningen HM, van de Putte $L B$, van den Berg WB: Degenerative knee joint lesions in mice after a single intraarticular collagenase injection. A new model of osteoarthritis. J Exp Pathol (Oxford) 1990, 71:19-31.

28. Inglis JJ, McNamee KE, Chia SL, Essex D, Feldmann M, Williams RO, Hunt SP Vincent $\mathrm{T}$ : Regulation of pain sensitivity in experimental osteoarthritis by the endogenous peripheral opioid system. Arthritis Rheum 2008, 58:3110-3119.

29. Bove SE, Flatters SJ, Inglis JJ, Mantyh PW: New advances in musculoskeletal pain. Brain Res Rev 2009, 60:187-201.

30. Plater-Zyberk C, Joosten LA, Helsen MM, Hepp J, Baeuerle PA, van den Berg WB: GM-CSF neutralisation suppresses inflammation and protects cartilage in acute streptococcal cell wall arthritis of mice. Ann Rheum Dis 2007, 66:452-457.

31. van Lent PL, Blom AB, Schelbergen RF, Sloetjes A, Lafeber FP, Lems WF, Cats $\mathrm{H}$, Vogl T, Roth J, van den Berg WB: Active involvement of alarmins S100A8 and S100A9 in the regulation of synovial activation and joint destruction during mouse and human osteoarthritis. Arthritis Rheum 2012, 64:1466-1476.

32. Pritzker KP, Gay S, Jimenez SA, Ostergaard K, Pelletier JP, Revell PA, Salter D, van den Berg WB: Osteoarthritis cartilage histopathology: grading and staging. Osteoarthritis Cartilage 2006, 14:13-29.

33. De Nardo CM, Lenzo JC, Pobjoy J, Hamilton JA, Cook AD: Urokinase-type plasminogen activator and arthritis progression: contrasting roles in systemic and monoarticular arthritis models. Arthritis Res Ther 2010, 12: R199.

34. Mercuri FA, Maciewicz RA, Tart J, Last K, Fosang AJ: Mutations in the interglobular domain of aggrecan alter matrix metalloproteinase and aggrecanase cleavage patterns. Evidence that matrix metalloproteinase cleavage interferes with aggrecanase activity. J Biol Chem 2000, 275:33038-33045.

35. van Meurs JB, van Lent PL, Holthuysen AE, Bayne EK, van den Berg WB: Kinetics of aggrecanase- and metalloproteinase-induced neoepitopes in various stages of cartilage destruction in murine arthritis. Arthritis Rheum 1999, 42:1128-1139.

36. Hughes CE, Caterson B, Fosang AJ, Roughley PJ, Mort JS: Monoclonal antibodies that specifically recognize neoepitope sequences generated by 'aggrecanase' and matrix metalloproteinase cleavage of aggrecan: application to catabolism in situ and in vitro. Biochem J 1995, 305(Pt 3):799-804.

37. Sellam J, Berenbaum F: The role of synovitis in pathophysiology and clinical symptoms of osteoarthritis. Nat Rev Rheumatol 2010, 6:625-635.

38. Hamilton JA, Tak PP: The dynamics of macrophage lineage populations in inflammatory and autoimmune diseases. Arthritis Rheum 2009, 60:1210-1221.

39. Felson DT, Gale DR, Elon Gale M, Niu J, Hunter DJ, Goggins J, Lavalley MP: Osteophytes and progression of knee osteoarthritis. Rheumatology (Oxford) 2005, 44:100-104

40. Kortekaas MC, Kwok WY, Reijnierse M, Huizinga TW, Kloppenburg M: Osteophytes and joint space narrowing are independently associated with pain in finger joints in hand osteoarthritis. Ann Rheum Dis 2011, 70:1835-1837.

41. Joosten LA, Helsen MM, van den Berg WB: Protective effect of rimexolone on cartilage damage in arthritic mice: a comparative study with triamcinolone hexacetonide. Agents Actions 1990, 31:135-142.

42. van Lent $\mathrm{PL}$, Blom $A B$, van der Kraan $\mathrm{P}$, Holthuysen $A E$, Vitters $E$, van Rooijen N, Smeets RL, Nabbe KC, van den Berg WB: Crucial role of synovial lining macrophages in the promotion of transforming growth factor beta-mediated osteophyte formation. Arthritis Rheum 2004, 50:103-111.

43. Schweizerhof M, Stosser S, Kurejova M, Njoo C, Gangadharan V, Agarwal N, Schmelz M, Bali KK, Michalski CW, Brugger S, Dickenson A, Simone DA, Kuner R: Hematopoietic colony-stimulating factors mediate tumor-nerve interactions and bone cancer pain. Nat Med 2009, 15:802-807.

44. Blom AB, van der Kraan PM, van den Berg WB: Cytokine targeting in osteoarthritis. Curr Drug Targets 2007, 8:283-292.

45. Hamilton JA: A colony-stimulating factor network involving mononuclear phagocytes and other cells. In Haemopoietic Growth Factors and Mononuclear Phagocytes. Edited by: van Furth R. Basel: Karger; 1993:29-35.

46. van Meurs JB, van Lent PL, Bayne EK, van de Loo FA, van den Berg WB: Interleukin-1 receptor antagonist prevents expression of the 
metalloproteinase-generated neoepitope VDIPEN in antigen-induced arthritis. Arthritis Rheum 1998, 41:647-656.

doi:10.1186/ar4037

Cite this article as: Cook et al:: Granulocyte-macrophage colony-

stimulating factor is a key mediator in experimental osteoarthritis pain and disease development. Arthritis Research \& Therapy 2012 14:R199.

Submit your next manuscript to BioMed Central and take full advantage of:

- Convenient online submission

- Thorough peer review

- No space constraints or color figure charges

- Immediate publication on acceptance

- Inclusion in PubMed, CAS, Scopus and Google Scholar

- Research which is freely available for redistribution

Submit your manuscript at www.biomedcentral.com/submit 